Shashi Dahiya ${ }^{1}$
S.S Handa
N.P Singh
JEL: G 21, E51

DOI: 10.5937/industrija43-8211

UDC: 005.585:336.77

658.148

Short Communication

\title{
Credit Scoring Using Ensemble of Various Classifiers on Reduced Feature Set
}

Article history:

Received: 3 May 2015

Sent for revision: 20 May 2015

Received in revised form: 2 September 2015

Accepted: 11 November 2015

Available online: 30 December 2015

\begin{abstract}
Credit scoring methods are widely used for evaluating loan applications in financial and banking institutions. Credit score identifies if applicant customers belong to good risk applicant group or a bad risk applicant group. These decisions are based on the demographic data of the customers, overall business by the customer with bank, and loan payment history of the loan applicants. The advantages of using credit scoring models include reducing the cost of credit analysis, enabling faster credit decisions and diminishing possible risk. Many statistical and machine learning techniques such as Logistic Regression, Support Vector Machines, Neural Networks and Decision tree algorithms have been used independently and as hybrid credit scoring models. This paper proposes an ensemble based technique combining seven individual models to increase the classification accuracy. Feature selection has also been used for selecting important attributes for classification. Cross classification was conducted using three data partitions. German credit dataset having 1000 instances and 21 attributes is used in the present study. The results of the experiments revealed that the ensemble model yielded a very good accuracy when compared to individual models. In all three different partitions, the ensemble model was able to classify more than $80 \%$ of the loan customers as good creditors correctly. Also, for 70:30 partition there was a good impact of feature selection on the
\end{abstract}

\footnotetext{
${ }^{1}$ Manav Rachna International University (MRIU), Department of Computer Science and Engineering.,Faridabad, India, shashi@iasri.res.in

${ }_{2}^{2}$ Manav Rachna International University (MRIU), Faridabad, India.

${ }^{3}$ Management Development Institute (MDI), India. 
Shashi D. et al.: Credit Scoring Using Ensemble of Various Classifiers on ...

accuracy of classifiers. The results were improved for almost all individual models including the ensemble model.

Keywords: Credit, Credit Scoring, Machine learning, Ensemble, Classification

\section{Ocena kreditne sposobnosti kombinovanjem različitih klasifikatora redukovanog skupa karakteristika}

Apstrakt: Finansijske i bankarske institucije $u$ velikoj meri koriste metode ocene kreditne sposobnosti prilikom evaluacije zahteva za izdavanje kredita. Kreditna ocena daje informaciju o tome da li podnosilac zahteva pripada grupi sa dobrim rizikom ili grupi sa lošim rizikom. Ove odluke se zasnivaju na demografskim podacima o klijentima, ukupnom poslovanju klijenta sa bankom $i$ istoriji otplate kredita koji je odobren podnosiocima. Prednosti korišćenja modela za određivanje kreditne ocene uključuju smanjenje troškova kreditne analize, omogućavanje bržih odluka o kreditu i smanjenje mogućeg rizika. Mnoge tehnike statističkog i mašinskog učenja, kao što su logistička regresija, mašine potpornih vektora, neuronske mreže $i$ algoritmi stabla odlučivanja, korišćene su i nezavisno i kao hibridni modeli kreditnog ocenjivanja. Ovaj rad predlaže tehniku koja se bazira na kombinovanju sedam pojedinačnih modela kako bi se povećala preciznost klasifikacije. Izbor karakteristika se takođe koristi za odabir važnih atributa za klasifikaciju. Unakrsna klasifikacija je sprovedena pomoću tri particije podataka. U studiji je korišćen skup podataka o odobrenim kreditima u Nemačkoj koji ima 1000 instanci i 21 atribut. Rezultati eksperimenata su otkrili da je model kombinovanja omogućio veliku preciznost $u$ odnosu na pojedine modele. $U$ tri različite particije, model kombinovanja je $u$ stanju da pravilno klasifikuje više od $80 \%$ korisnika kredita kao dobre poverioce. Pored toga, za partciju 70:30 postojao je dobar uticaj odabira karakteristika na tačnost klasifikatora. Rezultati su poboljšani za skoro sve pojedine modele uključujući model kombinovanja.

Ključne reči: kredit, kreditna ocena, mašinsko učenje, kombinovanje, klasifikacija.

\section{Introduction}

Classification is a process of assigning objects to one of several predefined categories. It is one of the most useful techniques in data mining to build 
Shashi D. et al.: Credit Scoring Using Ensemble of Various Classifiers on ...

classification models from an input data set. With classification, the generated model will be able to predict a class for a given instance depending on previously learned information from the historical data. Several studies used data mining for extracting rules and predicting certain behaviours in several areas of science, information technology, finance, education, biology and medicine. In past few decades, DM techniques have been widely used in the area of finance. Data were limited to the own databases of financial institutions but nowadays, some data are publicly available in several countries and financial institutions and researchers have developed many different quantitative credit scoring techniques (Sustersic et al., 2009). Credit scoring is a technique that helps lenders decide whether to grant credit to the applicants with respect to the applicants' characteristics such as age, income and marital status (Chen and Huang (2003)). The credit scoring models were initially proposed by (Fisher (1936)). These models were developed further in research done by (Altman (1968)), (Beaver (1967)) and others till now.

In the last few decades, various quantitative methods were proposed in the literature to evaluate consumer loans and improve the credit scoring accuracy. These models can be grouped into parametric and non-parametric models/ data mining models. The parametric models include the Linear Discriminant Analysis (LDA) (Reichert et al., 1983), Logistic regression (LR), Multivariate adaptive regression splines (MARS), and many others. However, both LDA and LR are of low classification accuracy in the credit scoring, as the relationship among variables is linear. To improve the less accuracy of parametric statistical methods, many models based on data-mining methods are built. These methods include the decision trees (DT) (Daviset al., 1992), (Frydman et al., 1985),(Zhou and Zhang (2008)); artificial neural networks (ANN) (Jensen (1992)), (West (2000)), (West et al., 2005); k-nearest neighbour (Henley and Hand (1996)), genetic programming (GP) (Abdou (2009)), (Onget al., 2005); genetic algorithm (GA) (Desai (1997)), (Walker et al.,1995), (Zhang et al., 2007); case-based reasoning (CBR) (Chuang and Lin (2009)), (Jo et al., 1997), (Park and Han (2002)); Artificial Immune System Algorithm (Leung et al., 2007); rule extraction based on NN (Setionoet al., 2008); classification based on association rules (Li et al., 2001), (Liu et al., 1998), (Yin and Han (2003)) and support vector machines (SVM) (Baesens et al., 2003), (Gestel et al., 2003), (Huang et al., 2007), etc.

Hybrid data mining approaches such as GA-ANN, PCA-ANN and LR-ANN (Sustersic (2009)), MARS-ANN (Lee and Chen (2005)), LR-ANN (Lin (2009)) and GA-SVM (Huang et al., 2007), CART+MARS, SVM (Chen et al., 2009) and others has resulted in better performance of model. A novel machine learning technique called Ensemble learning is also being used for improving accuracy. A classifier ensemble (also referred to as committee of learners, mixture of experts, multiple classifier system) consists of a set of individually trained classifiers (base classifiers) whose decisions are combined in some way, typically by weighted or un-weighted voting, when classifying new examples (Kittler et al., 1998), 
Shashi D. et al.: Credit Scoring Using Ensemble of Various Classifiers on ...

(Kuncheva (2004)). It has been found that in most cases the ensembles produce more accurate predictions than the base classifiers (Dietterich (1997)). Researchers have shown that aggregating approach can easily achieve improved accuracies by an aggregation of individual classifiers for credit scoring as well as the classification application. (Hoffmann et al., 2002) reported that the boosted genetic fuzzy classifier performed better than both the neuro fuzzy classifier and C4.5 algorithm. (West (2005)) reported that ensemble model of NNs obtained the higher accuracy than the single NN in credit scoring and bankruptcy prediction.

This paper presents an ensemble based credit scoring model for consumer loans. It is a feature selection based ensemble classifier in which an ensemble of 7 base classifiers is developed to form a classifier using a confidence-weighted voting method for enhancing the classification accuracy of the individual models. The performance of ensemble classifier is evaluated using the German credit dataset from the $\mathrm{UCl}$ Machine Learning Repository.

In the first section, an introduction to classification and credit scoring systems is given followed by the feature selection approach and ensemble approach. The second section describes the methodology of research having dataset description, model selection and model building. In the next section, model testing is done and the results are given. The results are discussed in the discussion section followed by the conclusion.

\subsection{Ensemble Approach}

There are three ways of classifying the training/ test instances into one of the predefined categories, they are: (1) individual, (2) hybrid, and (3) ensemble based approaches. Individual approach involves using a single statistical or machine learning method for classification. Ensemble approach weighs several individual classifiers, and combines them in order to obtain a classifier that outperforms every one of them. The important difference between hybrid methods and ensemble methods is that hybrid methods only use one classifier for sample learning and employ different way in feature selection and classifying stages, while ensemble learning produces various classifiers with different types or parameters, such as various SVM classifiers with different parameters, and train different samples for many times (Li and Zhong (2012)).

Ensemble learning has become the latest method of credit evaluation modelling. (Paleologo et al., 2010) proposed a hybrid credit evolution model based on Kmeans, SVM, decision trees and ada-boost algorithms and classify the samples by subagging ensemble approach. (Yu et al., 2008) employed ANN classifiers with different structures and used maximizing correlation to choose the ensemble members. (Nanni and Lumini (2009)) used random subspace ensemble approach. In this study, an ensemble approach based on confidence-weighted 
Shashi D. et al.: Credit Scoring Using Ensemble of Various Classifiers on ...

voting has been employed on 7 classifiers for classifying the credit dataset and enhancing the classification accuracy.

\section{$1.2 \quad$ Feature Selection}

It is a pre-processing technique that identifies a subset of input variables by eliminating features with little or no predictive information. Feature selection can significantly improve the comprehensibility of the resulting classifier models and often build a model that generalizes better to unseen points. Several feature selection methods are available with different search techniques to produce a reduced data set. This reduced data set improves accuracy compared with original dataset without altering the relevance or meaning of the data set.

The relationship between a feature selection algorithm (FSA) and the inducer chosen to evaluate the usefulness of the feature selection process can take three main forms: (1) Embedded, (2) Filter and (3) Wrapper. In scheme (1) the inducer has its own FSA (either explicit or implicit). The traditional machine learning tools like decision trees or artificial neural networks are included (Mitchell, 1982) in embedded scheme. In scheme (2), the feature selection process takes place before the induction step, and the former can be seen as a filter of non-useful features prior to induction. In a general sense it can be seen as a particular case of the embedded scheme in which feature selection is used as a pre-processing. The filter schemes are independent of the induction algorithm. In scheme (3), the relationship is taken the other way around: it is the FSA that uses the learning algorithm as a subroutine (John et al., 1994). It employs a search through the space of feature subsets using the estimated accuracy from an induction algorithm as the measure of goodness for a particular feature subset. From a set of hundreds or even thousands of predictors, the feature selection screens, ranks, and selects the predictors that are most important. The predictors, which contribute less in prediction, can be skipped from the data set. It provides a quicker, efficient model that uses fewer predictors, executes more quickly, and is easier to understand.

Present study considers the feature selection process based on Chi-Square statistic for identifying the important ones out of all predictor variables. Chi-Square statistic measures the lack of independence between a variable value and the class value. The Chi-Square model proposed by Karl Pearson has been used in the study. The features having the highest Chi-Square values for a particular class would prove to be the best in classification of the instances of that particular class. Thus, the first desired numbers of features, which have the highest ChiSquare values are selected. 
Shashi D. et al.: Credit Scoring Using Ensemble of Various Classifiers on ...

\section{Methodology of Research}

It is an empirical research paper. The cross classification was conducted on 3 partitions and then the feature selection process was applied based on Chisquare measure. The unimportant features were skipped and the performances on reduced set were compared against the performances of the classifiers using all features. The study was conducted in two steps, first taking all features as input and second taking only the reduced set. The Clementine tool was used to build and compare a number of different models for classifying the loan applicants into good and bad credit categories.

Objectives of Study: The objective of this study is to propose an ensemble classifier using feature selection along with cross classification for credit evaluation with the purpose of enhancing the classification accuracy of the individual models.

Research question: Can a combined effort of feature selection, cross classification and ensemble approach improve the classification accuracy of credit scoring models?

Data Set Used: The German credit scoring dataset of 1000 instances was taken from the $\mathrm{UCl}$ Machine Learning Repository. This dataset consists of 700 instances of creditworthy applicants and 300 instances of customers who should not have been granted the credit. In addition, it presents twenty (20) predictor variables for each credit applicant while there is one (1) response variable. All the variables are either integer or categorical in nature. There are two values in the class variable which are good and bad.

Variables: Predictor Variables: checking_status, duration, credit_history, purpose, credit_amount, savings_status, employment, installment_commitment, personal_status, other_parties, residence_since, property_magnitude, age, other_payment_plans, housing, existing_credits, job, num_dependents, own_telephone, foreign.

Response variable: class having two values good and bad.

Cross Classification/ Data Partitioning: The partitions of dataset were done in training and test data in ratios of 60:40, 70:30, and 50:50. The models were separately trained on $60 \%, 70 \%$ and $50 \%$ data and then tested on $40 \%, 30 \%$ and $50 \%$ data respectively. Pre-processing of dataset was done for identifying the missing values and the outliers.

\subsection{Model Selection}

Initially, 10 classifiers were taken to train on the credit dataset. These were: Neural Networks, C5.1, C\&R Tree, QUEST, CHAID, Logistic Regression, 
Shashi D. et al.: Credit Scoring Using Ensemble of Various Classifiers on ...

Decision List, Bayes Net, Discriminant Analysis and SVM. A set of candidate models have been generated and ranked. The models were ranked based on the overall accuracy of the models. The seven classifiers showing good training performance- the NNs, C5.1, CART Tree, QUEST, CHAID, LR and SVM (Fig. 1) were chosen as the base classifiers for the ensemble based experiments.

Fig.1. Individual Classifiers Performance Sorted by Overall Accuracy

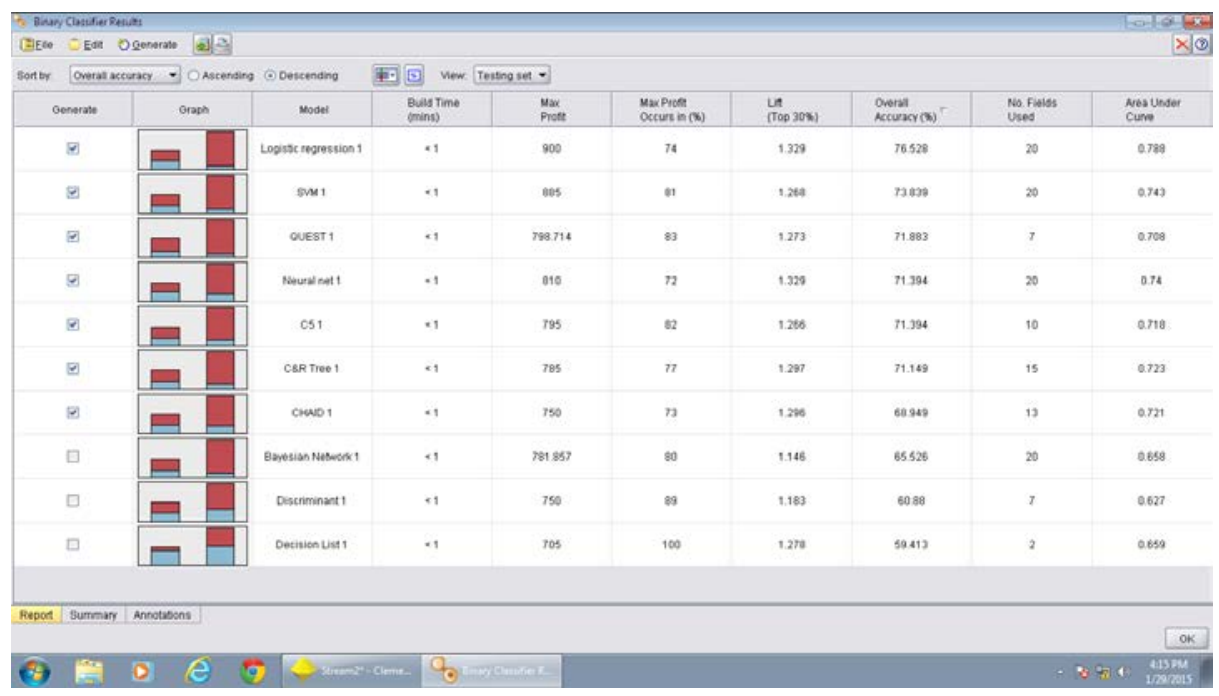

\subsection{Model Building}

First the dataset was partitioned into Training and Test instances. Then feature selection was applied and the important variables were selected. All the important fields were selected in the model based on the p-value (importance) for predictors using Chi-square measure. Out of 20 predictors 14 were ranked as important by the feature selection algorithm. These were: checking_status, duration, credit_history, purpose, credit_amount, savings_status, employment, instalment commitment, personal_status, property_magnitude, age, other_payment_plans existing_credits, and residence_since.

All the models were trained on the training instances of the data set with and without applying the feature selection. Then a single model was generated for each of the 7 selected classifiers. The seven generated models were combined using a combining method for ensemble models. The individual base models were combined using the confidence-weighted voting method, which determines how a single aggregated score is produced for each record. With simple voting, if two out of three models predict yes, then yes wins by a vote of 2 to 1 . But in case 
Shashi D. et al.: Credit Scoring Using Ensemble of Various Classifiers on ...

of confidence weighted voting, the votes are weighted based on the confidence value for each prediction. If one model predicts a 'no' with a higher confidence than the two 'yes' predictions combined, then the 'no' wins.

\section{Results}

The trained models were first tested on the trained and test set before applying the feature selection. The results of each individual model and the ensemble model without using feature selection are shown in Table 1. using cross classification on three different data partitions.

Table 1. Comparative Accuracy of classifiers without Feature Selection

\begin{tabular}{|l|l|l|l|l|l|l|l|}
\hline $\begin{array}{l}\text { Sr. } \\
\text { No }\end{array}$ & $\begin{array}{l}\text { Classifier } \\
\text { Used }\end{array}$ & \multicolumn{5}{|c|}{ Accuracy on Training and Test sets with cross } \\
classification
\end{tabular}

The performance on the test dataset is less than that of training dataset as all the models were already trained on the training set. For the test set, the classification was performed on the instances whose class labels were known but not presented to the model. The performance of the ensemble model was best followed by the LR model in all partitions. The performance of SVM, was also comparable to that of LR and better than NN, CART, C5.1, QUEST and CHAID. The classification accuracy of the ensemble model is $86.1 \%, 80.59 \%$ and $85.32 \%$ for 60:40, 70:30 and 50:50 partitions on test set without applying the feature selection for important attribute selection. The results of each individual model and the ensemble model using feature selection are shown in Table 2. along with cross classification on three different data partitions. 
Shashi D. et al.: Credit Scoring Using Ensemble of Various Classifiers on ...

Table 2. Comparative Accuracy of classifiers using Feature Selection

\begin{tabular}{|l|l|l|l|l|l|l|l|}
\hline S.N & Classifier & \multicolumn{6}{|c|}{ Accuracy on Training and Test sets with cross } \\
classification
\end{tabular}

The performance on the test dataset is less than that of training dataset in all cases. For the test set, the classification was performed on the instances whose class labels were known but not presented to the model. The performance of the Ensemble model was best for all partitions. The performance of LR and SVM models was comparable, but SVM performed best among individual models in 50:50 partition. The classification accuracy of the ensemble model is $82.90 \%$, $83.03 \%$ and $82.56 \%$ on $60: 40,70: 30$ and $50: 50$ partitions with reduced set obtained with feature selection process.

Comparison of Results with other Published Work: (Marques et al., (2012)) also performed experiments for building ensemble models using different base classifiers and shown that the C4.5, MLP and LR performed well whereas the nearest neighbour and the naive bayes classifiers appear to be significantly the worst. In similar experiments, (Wang et al., (2011)) shown that ensemble learning, enhanced the performance of the four base learners i.e., LR, DT, ANN and SVM. (Zhang and Yang (2008)) employed GA as the feature selector to facilitate the ensemble classifier to improve the overall sample classification accuracy while also identifying the most important features in the dataset of interest. The results suggest that this GA-Ensemble method outperformed other algorithms in comparison, and proved to be a useful method for classification and feature selection problems.

\section{Discussion}

Building the ensemble model using 7 base classifiers and combining them using the confidence-weighted voting yielded good results. The ensemble model had a very good accuracy when compared to individual models. In all three different partitions, the ensemble model was able to classify more than $80 \%$ of the loan 
Shashi D. et al.: Credit Scoring Using Ensemble of Various Classifiers on ...

customers as good creditors correctly. No enhancement in results was observed using the feature selection technique on the 60:40 and 50:50 partitions; instead the classification accuracy was decreased for the individual as well as the ensemble models. But using the 70: 30 partition there was good impact of feature selection. The results were improved for almost all individual models including the ensemble model on 70:30 partition.

\section{Conclusions}

This paper proposed an ensemble based technique combining selected base models to increase the classification accuracy. Feature selection has also been used for selecting important attributes for classification. Cross classification was conducted using three data partitions. From the results of the experiments it is concluded that the accuracy of ensemble based classifier is more than all single base classifiers on all partitions. It is also concluded that LR and SVM performed better than all other base classifiers individually. The impact of chi- square based feature selection method was good on only 70:30 partition, so other feature selection methods including wrapper based methods can be tested for getting better results. Also this methodology can be tested on other real time credit datasets using different combinations of the base classifiers.

\section{References}

Abdou, H.A. (2009). Genetic programming for credit scoring: The case of Egyptian public sector banks. Expert Systems with Applications, 36(9), 11402-11417.

Altman, E.I. (1968). Financial Ratios, Discriminant Analysis and the Prediction of Corporate Bankruptcy. Journal of Finance, 23(4), 589-609.

Baesens, B., Gestel, V., Viaene, S., Stepanova, M., Suykens, J., \& Vanthienen, J. (2003). Benchmarking state-of-the-art classification algorithms for credit scoring. Journal of the Operational Research Society, 54(6), 627-635. doi:10.1057/palgrave.jors.2601545

Beaver, W. (1967). Financial ratios as predictors of failures. Empirical Research in Accounting: Selected, 38(1), 63-93.

Chen, M.C., \& Huang, S.H. (2003). Credit scoring and rejected instances reassigning through evolutionary computation techniques. Expert Systems with Applications, 24(4), 433-441.

Chen, W.M., Ma, C.Q., \& Ma, L. . Mining the Customer Credit Using Hybrid Support Vector Machine Technique. Expert Systems with Applications, 36(4), 7611-7616.

Chuang, C.L., \& Lin, R.H. (2009). Constructing a reassigning credit scoring model, Part 1. Expert Systems with Applications, 36(2), 1685-1694.

Davis, R.H., Edelman, D.B., \& Gammerman, A.J. (1992). Machine-learning algorithms for credit-card applications. IMA Journal of Management Mathematics, 4(1), 4351. doi:10.1093/imaman/4.1.43 


\section{Shashi D. et al.: Credit Scoring Using Ensemble of Various Classifiers on ...}

Desai, V. (1997). Credit-scoring models in the credit-union environment using neural networks and genetic algorithms. IMA Journal of Management Mathematics, 8(4), 323-346. doi:10.1093/imaman/8.4.323

Dietterich, T.G. (1997). Machine-learning research: Four current directions. Al Magazine, 18(4), 97-136.

Fisher, R. (1936). The use of multiple measurements in taxonomic problems. Annals of Eugenics, 7, 179-188.

Frydman, H., Altman, E.I., \& Kao, D.L. (1985). Introducing recursive partitioning for financial classification: The case of financial distress. The Journal of Finance, 40(1), 269-291.

Gestel, T.V., Baesens, B., Garcia, J., \& Dijcke, P.V. (2003). A support vector machine approach to credit scoring. Bank en Financiewezen, 2, 73-82.

Henley, W.E., \& Hand, D.J. (1996). A k-Nearest-Neighbour Classifier for Assessing Consumer Credit Risk. Statistician,45(1), 77. doi:10.2307/2348414

Hoffmann, F., Baesens, B., Martens, J., Put, F., \& Vanthienen, J. (2002). Comparing a genetic fuzzy and a neurofuzzy classifier for credit scoring. International Journal of Intelligent Systems, 17(11), 1067-1083. doi:10.1002/int.10052

Huang, C.L., Chen, M.C., \& Wang, C.J. (2007). Credit scoring with a data mining approach based on support vector machines. Expert Systems with Applications, 33(4), 847-856.

Jensen, H.L. (1992). Using neural networks for credit scoring. Managerial Finance, 18(6), 15-26.

Jo, H., Han, I., \& Lee, H. (1997). Bankruptcy prediction using case-based reasoning, neural networks, and discriminant analysis. Expert Systems with Applications, 13(2), 97-108.

John, G.H., Kohavi, R., \& Pfleger, K. (1994). Irrelevant Features and the Subset Selection Problem. In: Proc. of the 11th Int. Conf. on Machine Learning. 121129.

Kuncheva, L.I. (2004). Combining pattern classifiers: Methods and algorithms. Hoboken, NJ: Wiley.

Lee, T., \& Chen, I. (2005). A two-stage hybrid credit scoring model using artificial neural networks and multivariate adaptive regression splines. Expert Systems with Applications, 28(4), 743-752. doi:10.1016/j.eswa.2004.12.031

Leung, K., Cheong, F., \& Cheong, C. (2007). Consumer credit scoring using an artificial immune system algorithm. In: IEEE congress on evolutionary computation. 3377-3384.

Li, W., Han, J., \& Pei, J. (2001). CMAR: Accurate and efficient classification based on multiple class-association rules. In:ICDM'01, CA: San Jose. 369-376.

Li, X.L., \& Zhong, Y. (2012). An Overview of Personal Credit Scoring: Techniques and Future Work. International Journal of Intelligence Science, 2012(2), 181-189.

Lin, S.L. (2009). A new two-stage hybrid approach of credit risk in banking industry. Expert Systems with Applications, 36(4), 8333-8341.

Liu, B., Hsu, W., \& Ma, Y. (1998). Integrating classification and association rule mining. In: KDD'98, NY. 80-86.

Mitchell, T.M. (1982). Generalization as Search. Artificial Intelligence, 18(2), 203-226.

Nanni, L., \& Lumini, A. (2009). An Experimental Comparison of Ensemble of Classifiers of Bankruptcy Prediction and Credit Scoring. Expert Systems with Applications, 36(2), 3028-3033. 


\section{Shashi D. et al.: Credit Scoring Using Ensemble of Various Classifiers on ...}

Ong, C., Huang, J., \& Tzeng, G. (2005). Building credit scoring models using genetic programming. Expert Systems with Applications, 29(1), 41-47. doi:10.1016/j.eswa.2005.01.003

Paleologo, G., Elisseeff, A., \& Antonini, G. (2010). Subagging for Credit Scoring Models. European Journal of Operational Research, 201(1), 490-499.

Park, C.S., \& Han, I. (2002). A case-based reasoning with the feature weights derived by analytic hierarchy process for bankruptcy prediction. Expert Systems with Applications, 23(3), 255-264.

Reichert, A.K., Cho, C.C., \& Wagner, G.M. (1983). An examination of the conceptual issues involved in developing credit-scoring models. $J$ of Busi. and Econ. Statistics, 1(2), 101-114.

Setiono, R., Baesens, B., \& Mues, C. (2008). Recursive neural network rule extraction for data with mixed attributes, neural networks. IEEE Transactions, 19, 299-307.

Sustersic, M., Mramor, D., \& Zupan, J. (2009). Consumer credit scoring models with limited data. Expert Systems with Applications, 36(3), 4736-4744.

Walker, R.F., Haasdijk, E., \& Gerrets, M.C. (1995). Credit evaluation, using a genetic algorithm. In Intelligent Systems for Finance and Business. (pp. 39-59).

West, D. (2000). Neural network credit scoring models. Computers and Operations Research, 27(11-12), 1131-1152.

West, D., Dellana, S., \& Qian, J.X. (2005). Neural network ensemble strategies for financial decision applications.Computers and Operations Research, 32(10), 2543-2559.

Yin, X., \& Han, J. (2003). CPAR: Classification based on predictive association rule. In: SDM, San Francisco, CA.

Yu, L., Wang, S., \& Lai, K. (2008). Credit risk assessment with a multistage neural network ensemble learning approach.Expert Systems with Applications, 34(2), 1434-1444. doi:10.1016/j.eswa.2007.01.009

Zhang, D.F., Huang, H.Y., Chen, Q.S., \& Jiang, Y. (2007). A comparison study of credit scoring models. Natural Computation, 1(15-18), 24-27.

Zhou, X.Y., Zhang, D.F., \& Jiang, Y. (2008). A new credit scoring method based on rough sets and decision tree. Lecture Notes in Artificial Intelligence, 5012, 10811089. 